\title{
Small GTP-binding Proteins: A Future for the Treatment of Cognitive Disorders?
}

Maria V Tejada-Simon ${ }^{1-3^{*}}$

${ }^{1}$ Department of Pharmacological and Pharmaceutical Sciences, University of Houston, 521 Science and Research Building 2, Houston, TX 77204, USA

${ }^{2}$ Department of Biology and Biochemistry, University of Houston, 369 Science and Research Building 2, Houston, TX 77204, USA

${ }^{3}$ Department of Psychology, University of Houston, 126 Heyne Building, Houston, TX 77204, USA

"Corresponding author: Maria V Tejada-Simon, University of Houston, 521 Science and Research Building 2, Houston, TX 77204, USA, Tel: 713-743-7835; Fax: 713-743-1884; E-mail: mvtejada-simon@uh.edu

Rec date: Jan 31, 2014, Acc date: Feb 27, 2014, Pub date: Mar 6, 2014

Copyright: (c) 2014 Maria V Tejada-Simon. This is an open-access article distributed under the terms of the Creative Commons Attribution License, which permits unrestricted use, distribution, and reproduction in any medium, provided the original author and source are credited.

\begin{abstract}
Recent findings indicate that early brain overgrowth could be a key factor in the patho-biology of autism and other disorder with learning disabilites, and that anomalous neuronal wiring might play a role when is affecting brain regions involved in cognition. Thus, precise synaptic connectivity is crucial for normal brain function and a common anatomical pathology associated with autism and cognitive disability is an alteration of that connectivity due to an irregular morphology of the dendritic spines in the neurons. For example, human patients as well as animal models of Fragile X syndrome (FXS), Neurofibromatosis, Tuberous sclerosis, and Rett syndrome, have shown a higher number of immature dendritic spines in certain regions of the brain, phenomena that has been linked with impaired learning and memory functions. However, how this deficiency is produced is not yet well understood. Evidence from our laboratory and others is pointing to a role of small GTP-binding proteins of the Rho family, which mediate actin cytoskeleton reorganization, neuronal morphogenesis and gene expression. We have reported that these proteins are critical for dendritic morphology and plasticity. They act not only in the developing brain but also in the mature nervous system. One of its members, Rac1 is highly expressed in the adult mouse hippocampus, a brain area that exhibits robust synaptic plasticity and is crucial for the acquisition of memories. Moreover, using pharmacological and genetic approaches we and others have demonstrated that Rac1 is necessary for normal long-term plasticity, spine development and learning. Interestingly, glutamate transmission, long-term plasticity and learning behavior are characteristically altered in autistic disorders that present aberrant neuronal development. Therefore, there might be a functional link between small GTP-binding proteins and certain characteristic phenotypes described in cognitive disorders and possibly autism that render interest on the small GTP-binding proteins as possible therapeutic targets for these disorders.
\end{abstract}

Keywords: Autism; Plasticity; Small GTPases; Behavior; Rac1

\section{Introduction}

\section{Small GTP-binding proteins: Rho family}

Small GTP-binding proteins are involved in many different cellular processes [1], but they are mostly known to have a role in the assembly and organization of the actin cytoskeleton [2-5], which is required for cell remodeling. There are two independent cycles that lead to their activation: (1) cycling between cytosolic and membrane-associated forms through the action of guanine dissociation inhibitor (GDI) proteins; and (2) the removal of bound GDP and loading of GTP [1] (via GEFs and GAPs). Coupling these two cycles appropriately is critical for interaction with their targets [6].

One of the many families of small GTPases, is the Rho family of small GTPases, which include Cdc42, Rho, and Rac. Members of this family have a function in the same signaling systems, but they might either antagonize or activate each other's functions. For example, activation of Rac induces lamellipodium formation, and activation of Cdc42 leads to filopodium development. Cdc42 can activate Rac, what suggests that filopodia might be intimately associated with lamellipodia. Likewise, Rac can activate Rho, which produces stress fibers and fiber retraction [7]. In the brain, activation of Rac supports neurite outgrowth [8] and activation of Rho results in an opposite reaction, which is neurite retraction.

Rac is a protein of $22-25 \mathrm{kDa}$ molecular weight and nearly 200 amino acid residues, with two closely related isoform: Racl and Rac 2. These two forms differ in their C-termini. Racl is ubiquitously expressed and contains polybasic amino acid residues. Rac 2 is restricted to hematopoietic cells and is less basic [9]. There is a third form of Rac, Rac 3, which is expressed in a variety of tissues, among them brain, but in very early stages of development. Its subcellular localization and/or binding to regulatory proteins differ from the other two isoforms, possibly due to a differential carboxyl-terminal end [10]. In general, Racl is widely known for its role in actin polymerization [11], production of superoxide generation, and gene transcription [5], as well as G1 cell cycle progression [12].

\section{Small GTP-binding proteins and neuronal morphology}

Very recent studies have proposed a model for Rho GTPasemediated dendritic arbor growth in which neural activity, through NMDA and AMPA receptors, activates Racl and decreases RhoA activation, leading to elaboration of dendritic arbors [13]. In neuronal cultures, Rac1 mediates axonal growth and guidance, and together with activation of $\mathrm{Cdc} 42$ promote the formation of lamellipodia and filopodia respectively [14]. In the brain, Racl has multiple functions through direct or indirect interactions with many different effector 
proteins. Rac1 and other small GTPases regulate neuronal morphogenesis by affecting the stability and assembly of the actin cytoskeleton [15]. Both Rac1-GAPs and -GEFs are enriched in the postsynaptic density, ideally positioned for regulation by glutamate receptors [16,17]. Moreover, Racl also functions in the development and structural plasticity of dendrites and dendritic spines [18-24]. As the primary recipients of excitatory inputs in the brain, dendirtic spines rely on the actin signaling [25-31] need a period. Spine development and maintenance is an actin dependent event that requires a dynamic cytoskeleton guided by key regulator proteins such as Rac1 [11,15,32]. Using a site-specific Rac1 knockout mouse model, we reported that these Racl deficient mice present aberrant dendritic spine morphology in brain areas where Racl was genetically removed, indicating that Racl is directly involved in the morphogenesis of neuronal spines $[33,34]$.

\section{Small GTP-binding proteins and synaptic plasticity}

Several studies have suggested that some small GTPases involved in the remodeling of the actin cytoskeleton are activated after LTP induction in the CA1 region of the hippocampus via NMDA receptor activation [35]. This suggests that small GTPases play also a role in plasticity at hippocampal synapses during LTP. More recently, Rac1 signaling pathway has been implicated in long term plasticity [36,37]. Both, long-term potentiation (LTP) and long-term depression (LTD) involve formation and elimination of synaptic structures. Rac1 is indeed required and critical for LTP and LTD [38]. Using a pharmacological approach, we demonstrated that NMDA and mGluR receptor activation leads to the activation of Rac1/PAK signaling, which in turn allows LTP and LTD induction respectively. Furthermore, the use of Rac1 inhibitors significantly impaired LTP and LTD. The same effect was observed when using a genetic approach, testing LTP and LTD induction in a site-specific Rac1 knockout mouse model [33,34]

\section{Small GTP-binding proteins and learning}

There is evidence that processes necessary for LTP might also be necessary for memory consolidation in mammals. For example, infusion of a NMDA receptor antagonist interferes with acquisition of spatial memory [35]. Other evidence includes the observations that saturation of LTP in vivo impairs spatial learning [39] and that this impairment has a similar time course of decay, as does LTP [40]. As Racl has been recently proposed as a critical protein for plasticity [36,37], its signaling pathway has been implicated in learning $[36,41,42]$. Many Racl-effector proteins have been associated with cognitive impairment disorders. As example, members of the PAK family have been associated with non-syndromic X-linked mental retardation [43], Fragile X syndrome [44] and Down syndrome [45]. Also, LIMK-1 has been linked to William's syndrome [46]. Additionally, other molecules that function downstream from Rac1 have been implicated in the occurrence and progression of other human pathologies that present cognitive problems, such as Alzheimer's (the p35/Cdk5 kinase) [47]. Rac1 itself has been associated to forms of cognitive disorders and X-linked mental retardation syndromes $[33,48]$. Interestingly, all these cognitive disorders present abnormalities in dendritic spine structure and plasticity, besides their cognitive disability. Thus, a common pathway in cognitive impairment and mental disability may be a perturbation of neural connectivity and plasticity, hindering the development of appropriate connections between brain regions. Alteration in Racl function might be involved in these phenomena.

\section{Small GTP-binding proteins and their therapeutic potential}

Promising manipulations and experiments from our and other laboratories have rescued abnormal effects of Racl in neuronal development, synaptic plasticity as well as learning and memory function. Constitutively activated RhoA and Rac1 induced by CNF1 in mice have led to rearrangement of cerebral actin cytoskeleton, enhanced neurotransmission and synaptic plasticity, and improved learning and memory in various behavioral tasks [41]. Similarly, recent examples have involved these proteins in autistic disorders. In animal models of Fragile X syndrome, lack of FMRP protein (causing Fragile $\mathrm{X}$ syndrome) appears to correlate with an excessive synthesis of Rac1 [33,34], or its downstream effectors, PAK and CYFIP1 [49], leading to aberrant Racl-induced actin remodeling, and possibly generating the characteristic aberrant morphology of dendritic spines, resulting in cognitive deficiencies. Consistent with this, it has been demonstrated that double negative PAK mice also yield deficits in memory together with abnormal neuronal morphology in the cortex and altered plasticity [50], suggesting that regulation of this Rac1 effector protein is important for synaptic plasticity and learning. Interestingly, our in vitro investigations show that antagonizing Rac1 to reduce its expression/activation levels in Fmr1 KO mice, rescues the exaggerated hippocampal LTD observed [33] as well as their susceptibility to suffer audiogenic seizures (unpublished data). Thus, this signaling pathway involving Racl/PAK could represent a novel therapeutic site for Fragile X syndrome and possibly autism therapy.

\section{Conclusion}

It is undeniable that available animal models of diseases linked to cognitive impairment as well as the availability of certain specific inhibitory drugs represent optimal methods for studying alteration of neuroplasticity. Because plasticity has been linked to memory function [5], one exciting possibility is that, in these disorders, defects in cognition could be related to an abnormal regulation of pathways that link neuronal connectivity, plasticity and learning: that is, the abnormal regulation of Racl-dependent actin reorganization. This opens the possibility in the future of learning disability being rescued through pharmacological manipulation of neuronal plasticity via the regulation of Rac1/PAK pathway. As Rac1 activity is important for the regulation of actin dynamics, receptor clustering [2,51] and plasticity, it is not surprising to see that loss of Racl in excitatory neurons in the hippocampus results in impaired long-term plasticity $[33,36]$. Conversely, excess Racl expression results in exaggerated long-term plasticity, as reported in FXS [52]. Rac1-dependent alterations in neuroplasticity as well as behavioral abnormalities have been seen in other psychiatric disorders such as depression and schizophrenia [53]. Presently, two agents that specifically inhibit Racl have been used in electrophysiological experiments to study the role of Rac1 in longterm plasticity in the mouse brain. One of them has been effective in rescuing aberrant phenotypes observed in FXS related to long-term plasticity [33] and behavior. We consider these findings to be important in view of different psychiatric disorders featuring cognitive impairment, structural deficiencies and aberrant plasticity.

In conclusion, Rac1/PAK modulates spine development, synaptic function and learning in the brain. Dysfunction of Rac1/PAK signaling may be responsible for aberrant phenotypes observed in cognitive disorders and autistic syndromes. These findings suggest that 
Rac1/PAK signaling may provide a functional link among altered dendritic spines, aberrant synaptic plasticity and cognition impairment in autistic disorders, pointing to Rac1/PAK as a novel therapeutic target to treat these disorders.

\section{Acknowledgements}

This work was supported by generous grants from the FRAXA Research Foundation, the Jérôme LeJeune Foundation (France), GEAR-UH grant program, and SGP-UH program (M.V.T.S).

\section{References}

1. Smith SJ, Rittinger K (2002) Preparation of GTPases for structural and biophysical analysis. Methods Mol Biol 189: 13-24.

2. Hall A (1994) Small GTP-binding proteins and the regulation of the actin cytoskeleton. Annu Rev Cell Biol 10: 31-54.

3. Narumiya S, Ishizaki T, Watanabe N (1997) Rho effectors and reorganization of actin cytoskeleton. FEBS Lett 410: 68-72.

4. Tapon N, Hall A (1997) Rho, Rac and Cdc42 GTPases regulate the organization of the actin cytoskeleton. Curr Opin Cell Biol 9: 86-92.

5. Van Aelst L, D'Souza-Schorey C (1997) Rho GTPases and signaling networks. Genes Dev 11: 2295-2322.

6. Caron E (2003) Rac signalling: a radical view. Nat Cell Biol 5: 185-187.

7. Mackay TF, Lyman RF, Hill WG (1995) Polygenic mutation in Drosophila melanogaster: non-linear divergence among unselected strains. Genetics 139: 849-859.

8. Leeuwen FN, Kain HE, Kammen RA, Michiels F, Kranenburg OW, et al. (1997) The guanine nucleotide exchange factor Tiam1 affects neuronal morphology; opposing roles for the small GTPases Rac and Rho. J Cell Biol 139: 797-807.

9. Hirshberg M, Stockley RW, Dodson G, Webb MR (1997) The crystal structure of human racl, a member of the rho-family complexed with a GTP analogue. Nat Struct Biol 4: 147-152.

10. Haataja L, Groffen J, Heisterkamp N (1997) Characterization of RAC3, a novel member of the Rho family. J Biol Chem 272: 20384-20388.

11. Ridley AJ, Hall A (1992) Distinct patterns of actin organization regulated by the small GTP-binding proteins Rac and Rho. Cold Spring Harbor Symposia on Quantitative Biology 57: 661-671.

12. Minden A, Lin A, Claret FX, Abo A, Karin M (1995) Selective activation of the JNK signaling cascade and c-Jun transcriptional activity by the small GTPases Rac and Cdc42Hs. Cell 81: 1147-1157.

13. Li X, Saint-Cyr-Proulx E, Aktories K, Lamarche-Vane N (2002) Racl and Cdc42 but not RhoA or Rho kinase activities are required for neurite outgrowth induced by the Netrin-1 receptor DCC (deleted in colorectal cancer) in N1E-115 neuroblastoma cells. J Biol Chem 277: 15207-15214.

14. Kozma R, Sarner S, Ahmed S, Lim L (1997) Rho family GTPases and neuronal growth cone remodelling: relationship between increased complexity induced by $\mathrm{Cdc} 42 \mathrm{Hs}$, Racl, and acetylcholine and collapse induced by RhoA and lysophosphatidic acid. Mol Cell Biol 17: 1201-1211.

15. Luo L (2000) Rho GTPases in neuronal morphogenesis. Nat Rev Neurosci 1: 173-180.

16. Chetkovich DM, Gray R, Johnston D, Sweatt JD (1991) N-methyl-Daspartate receptor activation increases cAMP levels and voltage-gated $\mathrm{Ca} 2+$ channel activity in area CA1 of hippocampus. Proc Natl Acad Sci U S A 88: 6467-6471.

17. Penzes P, Johnson RC, Kambampati V, Mains RE, Eipper BA (2001) Distinct roles for the two Rho GDP/GTP exchange factor domains of kalirin in regulation of neurite growth and neuronal morphology. J Neurosci 21: 8426-8434.

18. Luo L, Hensch TK, Ackerman L, Barbel S, Jan LY, et al. (1996) Differential effects of the Rac GTPase on Purkinje cell axons and dendritic trunks and spines. Nature 379: 837-840.
19. Threadgill R, Bobb K, Ghosh A (1997) Regulation of dendritic growth and remodeling by Rho, Rac, and Cdc42. Neuron 19: 625-634.

20. Ruchhoeft ML, Ohnuma S, McNeill L, Holt CE, Harris WA (1999) The neuronal architecture of Xenopus retinal ganglion cells is sculpted by rho-family GTPases in vivo. J Neurosci 19: 8454-8463.

21. Lee T, Winter C, Marticke SS, Lee A, Luo L (2000) Essential roles of Drosophila RhoA in the regulation of neuroblast proliferation and dendritic but not axonal morphogenesis. Neuron 25: 307-316.

22. Nakayama AY, Harms MB, Luo L (2000) Small GTPases Rac and Rho in the maintenance of dendritic spines and branches in hippocampal pyramidal neurons. J Neurosci 20: 5329-5338.

23. Tashiro A, Minden A, Yuste R (2000) Regulation of dendritic spine morphology by the rho family of small GTPases: antagonistic roles of Rac and Rho. Cereb Cortex 10: 927-938.

24. Wong WT, Faulkner-Jones BE, Sanes JR, Wong RO (2000) Rapid dendritic remodeling in the developing retine: dependence on neurotransmission and reciprocal regulation by Rac and Rho. J Neurosci 20: $5024-5036$

25. Harris KM (1999) Structure, development, and plasticity of dendritic spines. Curr Opin Neurobiol 9: 343-348.

26. Kandel ER, Kupfermann I, Iversen S (2000) In: Kandel ER, Schwartz JH and Jessell TM (Eds.), learning and Memory. Principles of Neural Science. (4thedn), McGraw-Hill, 1231-1246.

27. Nimchinsky EA, Sabatini BL, Svoboda K (2002) Structure and function of dendritic spines. Annu Rev Physiol 64: 313-353.

28. Wong RO, Ghosh A (2002) Activity-dependent regulation of dendritic growth and patterning. Nat Rev Neurosci 3: 803-812.

29. Matsuzaki M, Honkura N, Ellis-Davies GC, Kasai H (2004) Structural basis of long-term potentiation in single dendritic spines. Nature 429: 761-766.

30. Tolias KF, Bikoff JB, Burette A, Paradis S, Harrar D, et al. (2005) The Rac1-GEF Tiam1 couples the NMDA receptor to the activity-dependent development of dendritic arbors and spines. Neuron 45: 525-538.

31. Gao FB (2007) Molecular and cellular mechanisms of dendritic morphogenesis. Curr Opin Neurobiol 17: 525-532.

32. Calabrese B, Wilson MS, Halpain S (2006) Development and regulation of dendritic spine synapses. Physiology (Bethesda) 21: 38-47.

33. Bongmba OY, Martinez LA, Elhardt ME, Butler K, Tejada-Simon MV (2011) Modulation of dendritic spines and synaptic function by Rac1: a possible link to Fragile X syndrome pathology. Brain Res 1399: 79-95.

34. Tejada-Simon MV, Bongmba OYN (2012). Regulation of neuronal morphology and plasticity by small GTP-binding proteins Implications for autism and mental retardation disorders. In Horizons in Neuroscience Research. Volume 8. Editors Andres Costa and Eugenio Villalba NOVA Science Publishers Hauppauge NY, USA.

35. O'Kane EM, Stone TW, Morris BJ (2003) Activation of Rho GTPases by synaptic transmission in the hippocampus. J Neurochem 87: 1309-1312.

36. Haditsch U, Leone DP, Farinelli M, Chrostek-Grashoff A, Brakebusch C, et al. (2009) A central role for the small GTPase Racl in hippocampal plasticity and spatial learning and memory. Mol Cell Neurosci 41: 409-419.

37. Martinez LA, Tejada-Simon MV (2011) Pharmacological inactivation of the small GTPase Racl impairs long-term plasticity in the mouse hippocampus. Neuropharmacology 61: 305-312.

38. Morris RG (1989) Synaptic plasticity and learning: selective impairment of learning rats and blockade of long-term potentiation in vivo by the $\mathrm{N}$ methyl-D-aspartate receptor antagonist AP5. J Neurosci 9: 3040-3057.

39. Moser EI, Krobert KA, Moser MB, Morris RG (1998) Impaired spatial learning after saturation of long-term potentiation. Science 281: 2038-2042.

40. Castro CA, Silbert LH, McNaughton BL, Barnes CA (1989) Recovery of spatial learning deficits after decay of electrically induced synaptic enhancement in the hippocampus. Nature 342: 545-548. 
Citation: Tejada-Simon (2014) Small GTP-binding Proteins: A Future for the Treatment of Cognitive Disorders?. Brain Disord Ther 3: 114. doi: 10.4172/2168-975X.1000114

Page 4 of 4

41. Diana G, Valentini G, Travaglione S, Falzano L, Pieri M, et al. (2007) Enhancement of learning and memory after activation of cerebral Rho GTPases. Proc Natl Acad Sci U S A 104: 636-641.

42. Martinez LA, Klann E, Tejada-Simon MV (2007) Translocation and activation of Rac in the hippocampus during associative contextual fear learning. Neurobiol Learn Mem 88: 104-113.

43. Allen KM, Gleeson JG, Bagrodia S, Partington MW, MacMillan JC, et al (1998) PAK3 mutation in nonsyndromic X-linked mental retardation. Nat Genet 20: 25-30.

44. Hayashi ML, Rao BS, Seo JS, Choi HS, Dolan BM, et al. (2007) Inhibition of p21-activated kinase rescues symptoms of fragile X syndrome in mice. Proc Natl Acad Sci U S A 104: 11489-11494.

45. Li W, Guan KL (2004) The Down syndrome cell adhesion molecule (DSCAM) interacts with and activates Pak. J Biol Chem 279: 32824-32831.

46. Donnai D, Karmiloff-Smith A (2000) Williams syndrome: from genotype through to the cognitive phenotype. Am J Med Genet 97: 164-171.

47. Maccioni RB, Otth C, Concha II, Muñoz JP (2001) The protein kinase Cdk5. Structural aspects, roles in neurogenesis and involvement in Alzheimer's pathology. Eur J Biochem 268: 1518-1527.
48. Chelly J, Mandel JL (2001) Monogenic causes of X-linked mental retardation. Nat Rev Genet 2: 669-680.

49. Castets M, Schaeffer C, Bechara E, Schenck A, Khandjian EW, et al. (2005) FMRP interferes with the Racl pathway and controls actin cytoskeleton dynamics in murine fibroblasts. Hum Mol Genet 14: 835-844.

50. Hayashi ML, Choi SY, Rao BS, Jung HY, Lee HK, et al. (2004) Altered cortical synaptic morphology and impaired memory consolidation in forebrain- specific dominant-negative PAK transgenic mice. Neuron 42: 773-787.

51. Wiens K, Lin H, Liao D (2005) Rac1 induces the clustering of AMPA receptors during spinogenesis. J Neurosci 25: 10627-10636.

52. Huber KM, Gallagher SM, Warren ST, Bear MF (2002) Altered synaptic plasticity in a mouse model of fragile X mental retardation. Proc Natl Acad Sci U S A 99: 7746-7750.

53. Elhardt M, Martinez L, Tejada-Simon MV (2010) Neurochemical, behavioral and architectural changes after chronic inactivation of NMDA receptors in mice. Neurosci Lett 468: 166-171. 